\title{
Commodity Export Prices and Exchange Rate: An Australian Perspective
}

\author{
Rajiv Bhar $^{1}$ \\ ${ }^{1}$ Queensland University of Technology, Australia \\ Correspondence: Rajiv Bhar, Queensland University of Technology, Australia. E-mail: \\ rajiv.bhar@connect.qut.edu.au \\ Received: November 5, 2014 \\ Accepted: November 17, 2014 \\ Online Published: December 25, 2014 \\ doi:10.5539/ijef.v7n1p1 \\ URL: http://dx.doi.org/10.5539/ijef.v7n1p1
}

\begin{abstract}
The impact of export commodity prices on the Australian dollar/US dollar exchange rate is investigated. Within a regression framework, the effect of four commodity sub-indices as generally favoured by the Reserve Bank of Australia is explored. These are Rural, Non-Rural, Base Metal and Bulk commodities. The aim is to find, if any, whether a particular category of commodities correlates especially well with changes in exchange rate given the commodities boom that Australia has recently experienced. The Non-Rural commodity sub-index appears to have the most explanatory power. The inclusion of the Balance of Trade variable shows a marginal improvement in the explanatory power.
\end{abstract}

Keywords: commodity price index, exchange rate, balance of trade

\section{Introduction}

The exchange rate of a currency, for example the Australian Dollar (AUD), is determined by the demand for it relative to another currency, say the US Dollar (USD). In general, demand for AUD is generated when Australian goods and services are sold, as these are priced in AUD. This is then balanced by the import of goods and services by Australia, as AUD needs to be sold to purchase the currency in which these imports are priced.

Commodities (raw materials or primary agricultural goods) have accounted for around 55\% of Australia's total export value and $11 \%$ of GDP (Robinson, 2013). With such a large share of Australia's exports, this means that a change in commodity prices is likely to affect the demand for AUD and thus influence the exchange rate.

There are many other factors that affect exchange rates such as cross-country differences in money supply, interest rates, output or inflation rates, but these are endogenous variables as they themselves are affected by the exchange rate. Commodity prices, however, are an exogenous variable for Australia. This is because the price of commodities is dictated globally and Australia is seen as a price-taker since the total volume of its commodity exports is relatively small compared to the total world volume (Chen, Rogoff, \& Rossi, 2010). There are certain commodities for which Australia has a large degree of market power, but these products can be easily substituted for others if their prices rise too high (i.e., if price of beef gets too high, people may switch to lamb as a substitute). This limits the effect that changes in Australia's exchange rate has on the world price of a commodity, enabling it to be considered exogenous.

Utilising this property, modelling of commodity prices and exchange rates has been undertaken in the literature to determine the predictive capacities of either for the other. In 2010, Chen, Rogoff and Rossi (CRR) found using quarterly data from spot markets that the exchange rates of a basket of five commodity-exporting countries with floating exchange rates (including Australia) could predict global commodity prices. The reasoning they offered to explain this finding was that purchasers of commodities know the size of the order that they will make and so buy the relevant currency ahead of time. This has the advantage of locking in a certain exchange rate, which aids in cash flow management. Thus information about the future demand for commodities is embedded in the exchange rate of these commodity-exporting countries.

Chan, Tse and Williams (2011) (CTW) dispute this finding. They modelled the same basket of countries bar one (Chile) but utilised daily data from futures markets. A futures market is where futures contracts are traded. These are agreements between two parties to buy or sell a specified asset of a set quality and quantity at a price agreed upon today, but with payment and delivery occurring at a specified future date. CTW did not find that exchange 
rates could predict commodity prices in their models and offer a possible explanation. Commodity futures markets allow individual and institutional investors to trade in assets that they could not access in the commodity spot and forward markets. The fact that the contract itself is traded as opposed to the actual good introduces high volumes of speculative transactions. This combined with the fact that investors can trade simultaneously in the commodities and currency futures market on a real time basis means that commodity prices and the exchange rates are more closely linked and responsive to each other, removing the predictive ability of exchange rates found by CRR.

Regardless of whether exchange rates present a predictive capacity, it is clear from both papers that there is a strong correlation between the collection of exchange rates for commodity-exporting countries Australia, Canada, New Zealand, South Africa and world commodity prices. Given that commodities comprise a significant percentage of these countries' total exports, this strong correlation should appear for each of their individual exchange rates.

Indeed Simpson (2002) investigated the relationship between commodity prices and the Australian Dollar. Using monthly commodity price index data from the Reserve Bank of Australia (RBA), he found a significant negative relationship between commodity price changes and AUD/USD exchange rate changes in the short term. His models also showed causality running from commodity price first differences to AUD/USD exchange rate first differences, which confirm Australia as a price-taker and that commodity price changes as exogenously determined.

This paper will further investigate the relationship between commodity prices and the AUD/USD exchange rate by using RBA monthly commodity index data split in to sub-indices representing different types of commodities. The aim is to determine the how price changes in each type of commodity correlate with changes in exchange rate. For example since Australia has just been through a mining boom, do changes in the price of mining products correlate strongly with changes in the AUD/USD exchange rate?

\section{Data and Methodology}

\subsection{Population and Sample}

To represent commodity prices (expressed in AUD), the RBA index of commodity prices (ICP) is used. It is a weighted average, where the weight given to each commodity reflects its importance in a base period to the total value of commodity exports from Australia. The latest revision in 2013 includes 21 major commodities that accounted for over 90\% of Australia's commodities export earnings in 2011/12 (Robinson, 2013). These 21 commodities are split across 4 categories: Rural, Non-Rural, Base Metals and Bulk Commodities from which 4 sub-indices are created (Note 1). This paper uses the entirety of the data available, which is from July 1982 to July 2014 on a monthly basis. This covers the whole period in which Australia has had a market-based exchange rate as the Australian Dollar was floated in December 1983.

The AUD/USD exchange rate is used as opposed to say the AUD/GBP (Great British Pound) exchange rate because the USD is considered the world currency, in which global prices are generally set. As the exchange rate varies rapidly on a daily basis, this paper uses the AUD/USD exchange rate taken on last day of each month from July 1982 to July 2014 to represent the exchange rate for that month.

In addition to commodity prices, the balance of trade (BoT) measure for Australia is considered as an explanatory variable for exchange rate changes. The BoT is simply total exports minus total imports over a certain time period. It was thought that by capturing some information about the selling of AUD (to buy imports) the model developed could better capture changes in the AUD/USD exchange rate. A possible concern is that the BoT is strongly related to the commodity sub-index variables, but little correlation was found.

Monthly Data for the BoT was only available from January 1988. Therefore when it was added to the model, the data for the other variables was cropped to match. Although this represents some loss in information, the sample size is still large enough for conclusions about the relationship between variables to be made. Plots of the raw data are shown in Figures 1-3 with their sources listed in references as RBA (2014 a, b, c) and ABS (2014 a, b). 


\section{Exchange Rate}

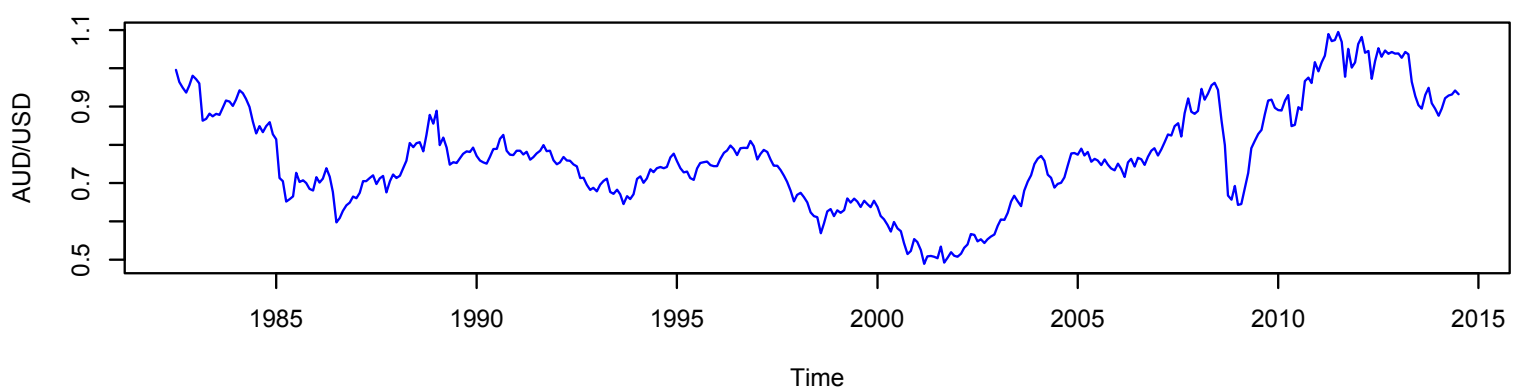

Figure 1. Raw data plot of AUD/USD exchange rate

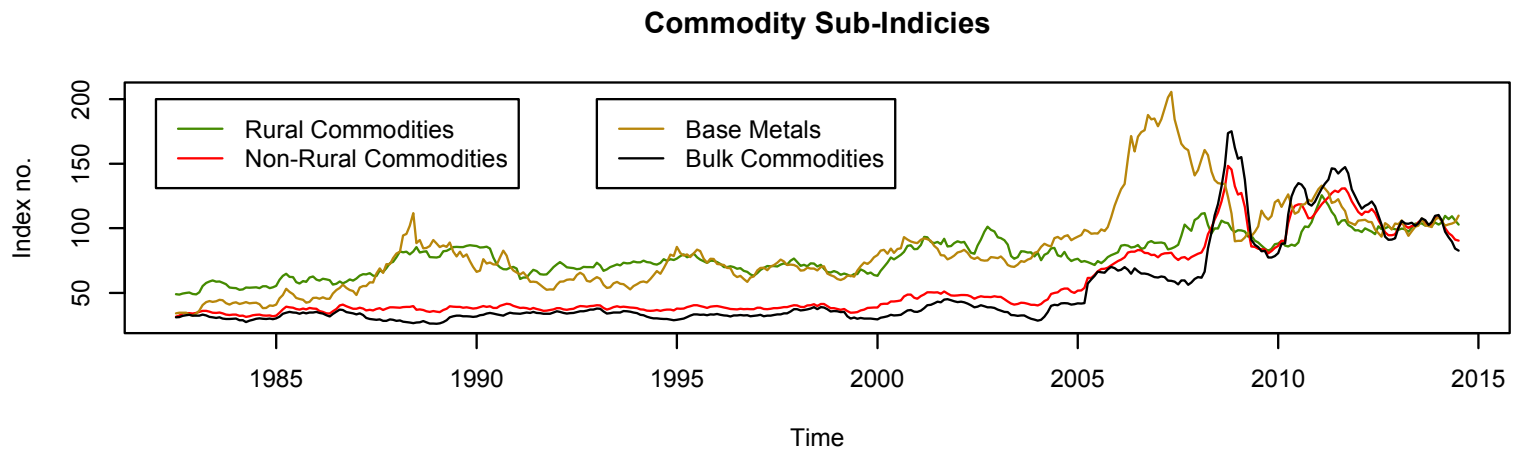

Figure 2. Raw data plot of the commodity sub-indices

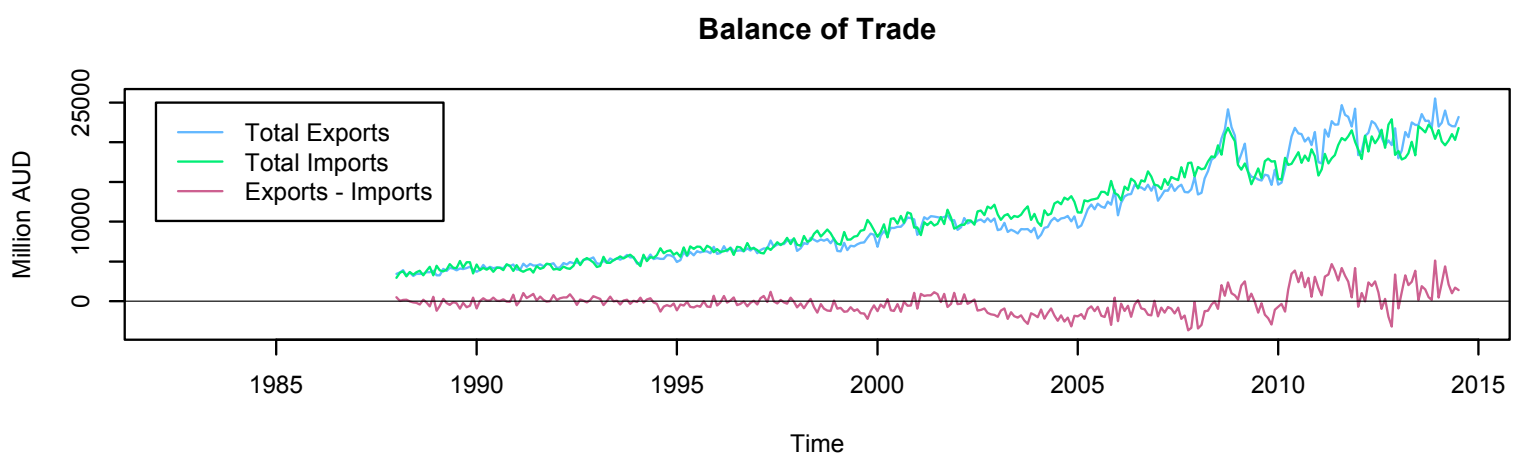

Figure 3. Raw data plot of the balance of trade

\subsection{Methodology}

A regression model attempting to explain changes in exchange rate with changes in commodity sub-indices and BoT is constructed using the method of Ordinary Least Squares (OLS). However, as the datasets being discussed are clearly examples of time series data, some care needs to be taken in order to produce a valid model.

Time series data differs from cross-sectional data in that samples are ordered in time, which means that, unlike cross-sectional data, they have not been randomly drawn from an existing population. However, the collected time series data set can be considered as a single realization of the outcomes of a random variable (e.g. Exchange Rate), which could have been different if history had played out in another way. This set of possible realizations then, is the population from which the collected time-series data is sampled (Wooldridge, 2013).

In order for statistical inferences to be made for a model of time series data constructed with OLS in the same way as for cross-sectional data, there are six classical regression model assumptions that must be met. 1) Explanatory variables have to be combined linearly. 2) No explanatory variable can be constant or a perfect linear combination of the others. 3) The expected value for the error term conditional on the explanatory variable across all time periods is zero. 4) The variance of the error is constant across all time periods (homoscedastic). 5) Errors in two different time periods are uncorrelated (no serial correlation). 6) Errors are independent of 
explanatory variables and are independently and identically distributed as Normal (Wooldridge, 2013).

One of the most difficult assumptions for a model to satisfy is assumption 3 , which requires the error at time $t$ be uncorrelated with each explanatory variable in every time period. If this is satisfied, then the explanatory variables are said to be strictly exogenous. One way to express this is that explanatory variables that are strictly exogenous cannot react to what has happened to the dependent variable in the past (Wooldridge, 2013). For this paper, it means that neither commodity prices nor BoT change as a result of changes in AUD/USD exchange rate. As this may not be the case, the model constructed may fail assumption 3.

In this situation, the large sample properties of OLS must be appealed to. This requires that the dependent and explanatory variables be stationary and weakly dependent. A stationary time series can be thought of as follows. If one takes a sequence of random variables (i.e., a sequence of exchange rates) and shifts it ahead by a certain time period, then the joint probability distribution should be unchanged. Although it is difficult to determine a stationary process, it is easy to spot a non-stationary one. A process with a time trend is not stationary as its mean changes over time. In addition, a stationary time series can be said to weakly dependent if data point $x_{t}$ and $x_{t+h}$ are "almost independent" as $h$ increases (Wooldridge, 2013).

Once dependent and explanatory variables can be considered stationary and weakly dependent, then assumption 3 is weakened to only requiring that the expected value of the error term conditional on the explanatory variable in the same time period is zero. That is, the explanatory variables are contemporaneously exogenous. Similarly, assumption 4 is weakened to only requiring contemporaneous homoscedasticity. Once these assumptions are met, it allows the test statistics and standard errors of OLS to be valid asymptotically, enabling their use just as for cross-sectional data (Wooldridge, 2013).

Unfortunately the exchange rate and commodity sub-indices cannot be considered to be stationary and weakly dependent in their raw form. However, taking the first difference of these time series renders them weakly dependent and most likely stationary (Wooldridge, 2013). Thus after taking the natural logarithm of each variable to adjust for scale, the exchange rate and commodity sub-indices are first differenced i.e. the log of the exchange rate for June, 2014 is subtracted from the log of the exchange rate for July, 2014 to form a new data point. For the BoT, natural logarithms of total exports and imports are taken and then subtracted to form ' $1 \mathrm{nBoT}$ ', since the BoT is not strictly positive.

Thus the model constructed in this paper will be of the form:

$$
\Delta \ln y_{t}=\beta_{0}+\beta_{1} \Delta \ln x_{1, t}+\beta_{2} \Delta \ln x_{2, t}+\ldots+\beta_{n} \Delta \ln x_{n, t}+u_{t}
$$

Where $\Delta$ represents the first difference, $y_{t}$ represents the dependent variable, $x_{n, t}$ represent the explanatory variables, $u_{t}$ represents the error term and $\beta_{n}$ represents the constants to be estimated. This paper will use backward stepwise regression (eliminating explanatory variables) to arrive at a suitable model.

It should be noted that this is a static model where each observation $\left(y_{t}\right)$ modelled depends only on the contemporaneous values of explanatory variables $\left(x_{n, t}\right)$. The implication of this structure is that interactions among the variables of the model are assumed to take place within the time period used for data sampling. This is reasonable when applied to the monthly data used in this paper, as the observation interval is long enough to allow interactions between changes in the exchange rate, changes in the commodity sub-indices and BoT to be absorbed.

\section{Results and Analysis}

Plots of the first differenced data for the AUD/USD exchange rate and commodity sub-indices in addition to "InBoT" are shown in Figures 4-9. This transformation of data is commonly interpreted as the continuous compounded return in holding the asset for a period of time, but for this paper it is more useful to think in terms of how changes in the explanatory variables affect changes in the exchange rate. 


\section{Exchange Rate}

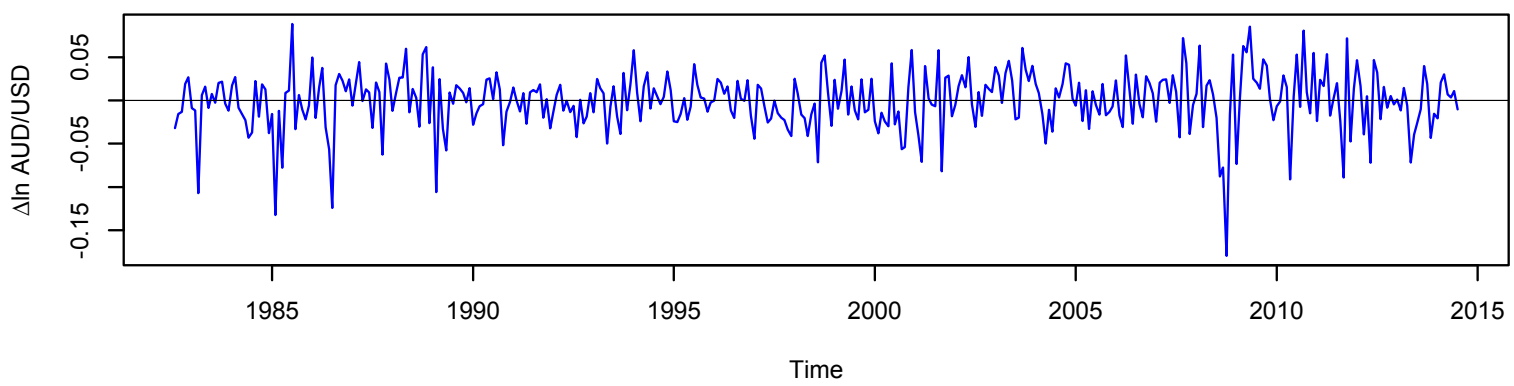

Figure 4. First differenced data plot of AUD/USD exchange rate

\section{Rural Commodities}

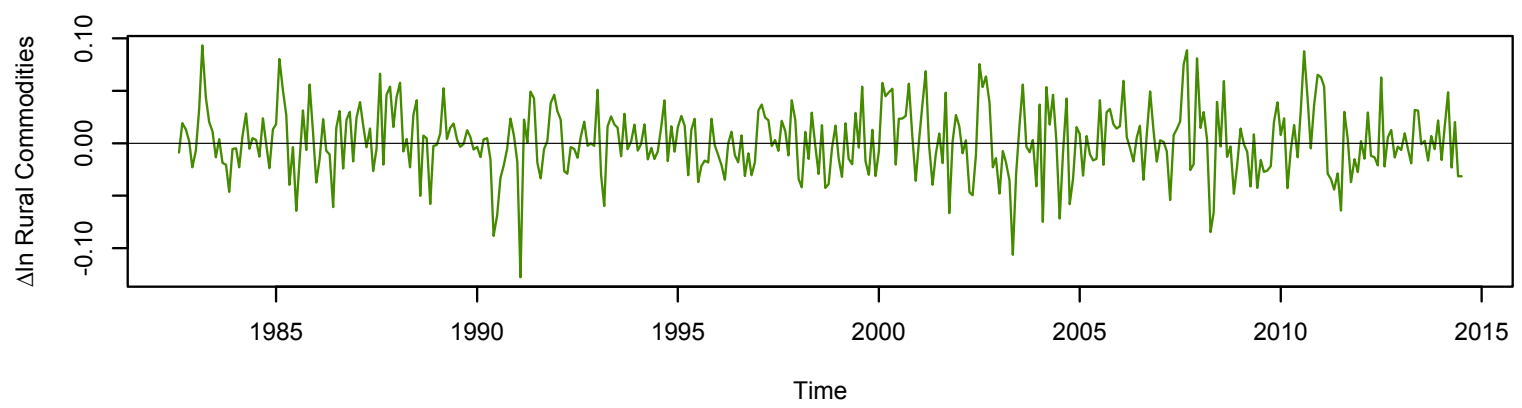

Figure 5. First differenced data plot of the rural commodity sub-index

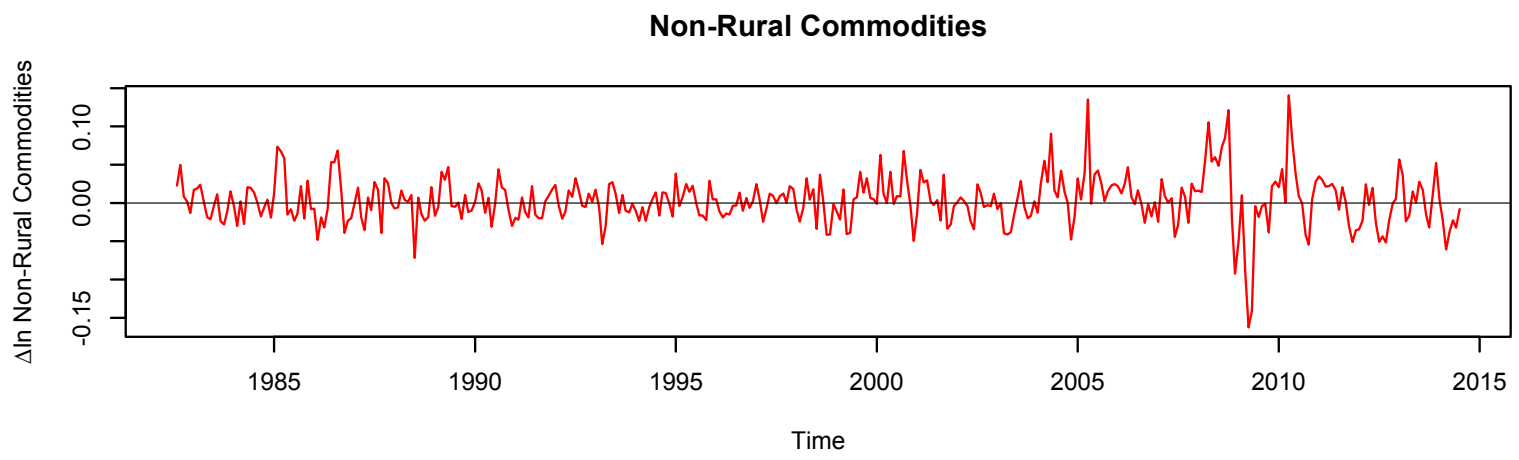

Figure 6. First differenced data plot of the Non-Rural commodity sub-index

\section{Base Metals}

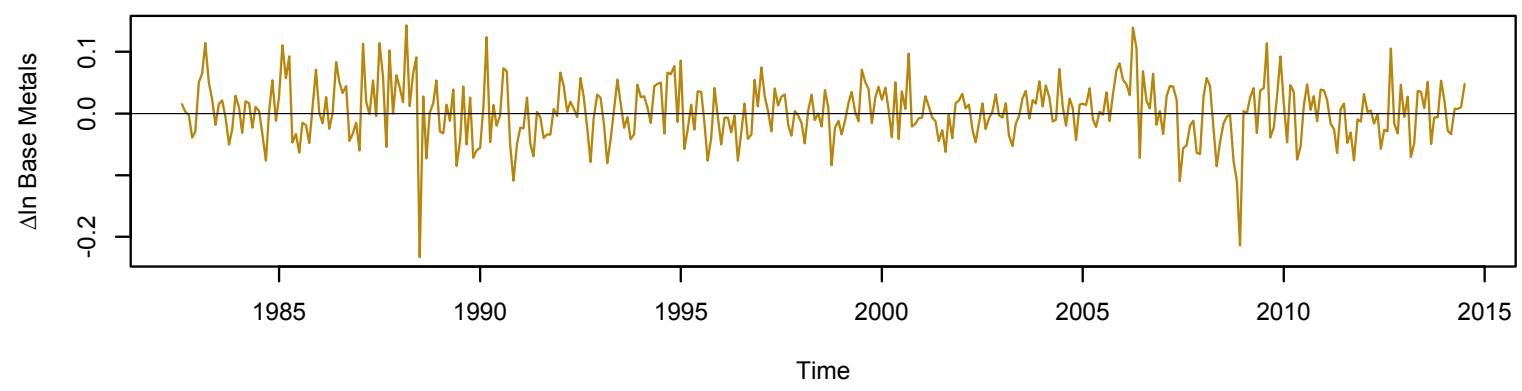

Figure 7. First differenced data plot of the base metal commodity sub-index 


\section{Bulk Commodities}

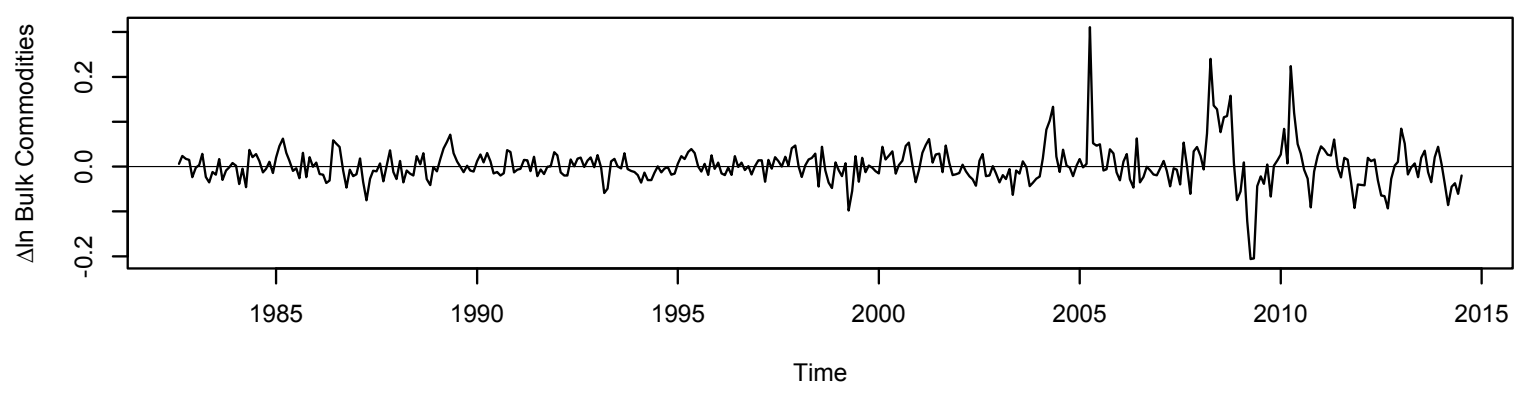

Figure 8. First differenced data plot of the bulk commodities sub-index

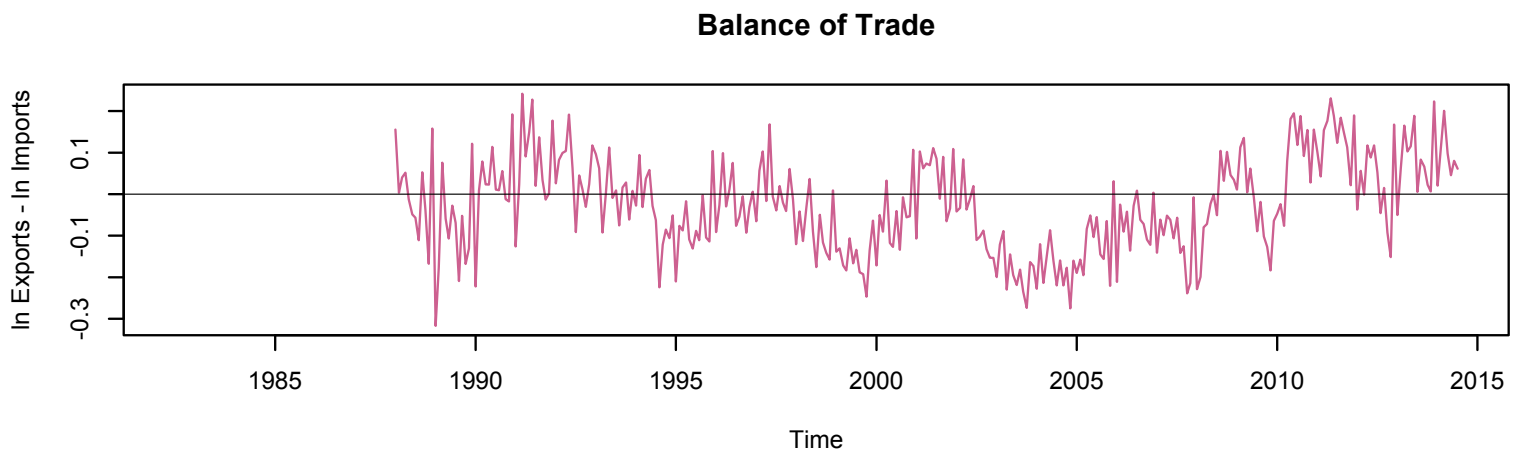

Figure 9. Plot of the log of exports minus the log of imports

The first set of models developed utilised only the commodity sub-indices for the explanatory variables, which meant that the sample size considered was from July, 1982 to July, 2014. Model 1 took the following form:

$$
\triangle \ln \operatorname{ExAUDUS}_{t}=\beta_{0}+\beta_{1} \Delta \ln \operatorname{ComR}_{t}+\beta_{2} \Delta \ln \operatorname{ComNR}_{t}+\beta_{3} \Delta \ln \operatorname{ComBM}_{t}+\beta_{4} \Delta \ln \operatorname{ComBC}_{t}+u_{t}
$$

Table 1. Model 1 coefficients

\begin{tabular}{lcccc}
\hline & Estimate & Std. Error & $\mathrm{t}$ value & $\operatorname{Pr}(>|\mathrm{t}|)$ \\
\hline (Intercept) & 0.00132 & 0.00149 & 0.88910 & 0.37451 \\
$\Delta \operatorname{lnComR}$ & -0.24303 & 0.04821 & -5.04099 & 0.000001 \\
$\Delta \operatorname{lnComNR}$ & -0.41380 & 0.12306 & -3.36262 & 0.00085 \\
$\Delta \operatorname{lnComBM}$ & 0.05676 & 0.04485 & 1.26545 & 0.20649 \\
$\Delta \ln$ ComBC & -0.02479 & 0.08180 & -0.30299 & 0.76206 \\
\hline
\end{tabular}

It can be seen from Table 1, which shows the coefficients, t-statistic and corresponding p-value of model 1, that only the rural commodity $(\Delta \operatorname{lnComR})$ and non-rural commodity sub-indices are significant. From Figures 6 and 8 , it appears visually that the non-rural and bulk commodity sub-indices are very similar and could be expressing similar information. A scatter plot of the two sub-indices against each other is shown in Figure 10. 


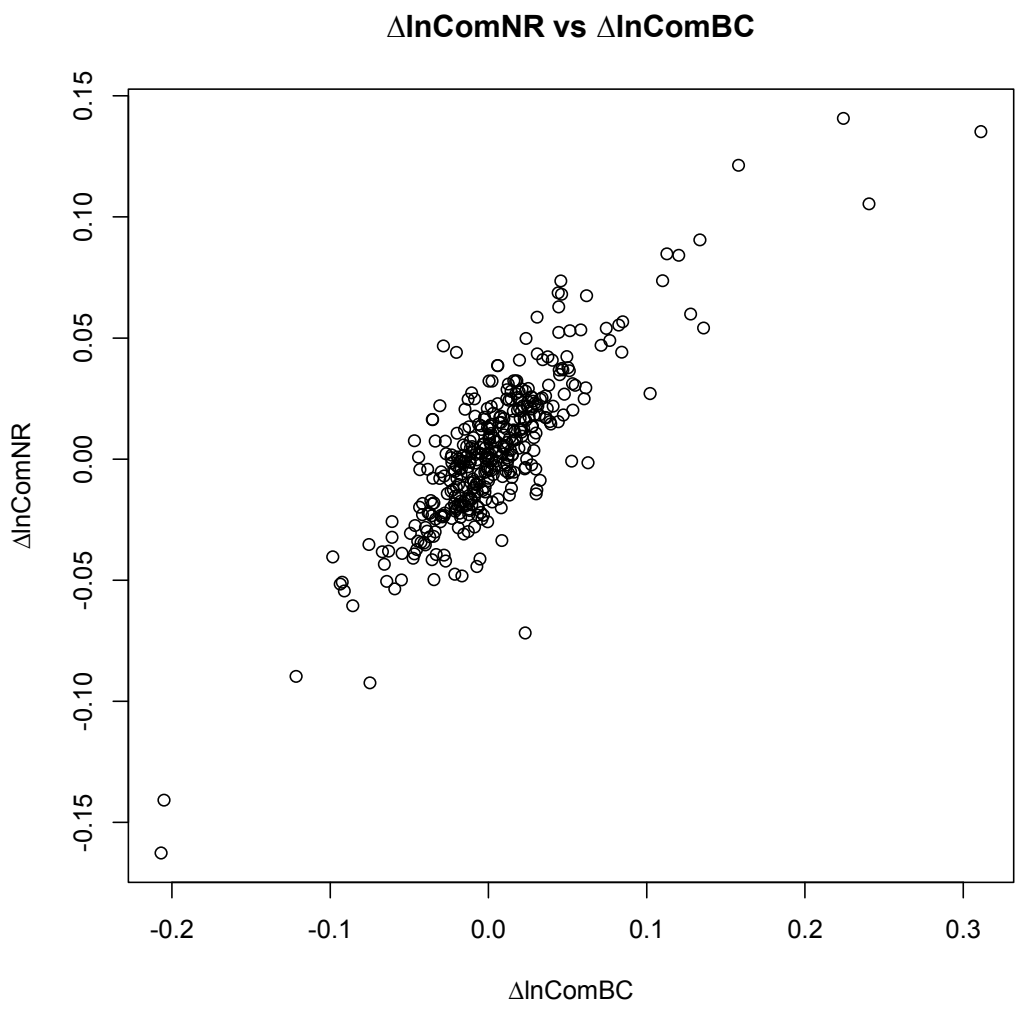

Figure 10. Plot of non-rural sub-index against bulk commodity sub-index

A clear linear trend exists between the non-rural and bulk commodity sub-indices, which is confirmed by a correlation value of 0.8452 . This can be explained by the structure of the sub-indices. The non-rural sub-index is comprised of the commodities contained within the base metal and bulk commodity sub-indices as well as LNG, Alumina, Crude Oil, Gold and Copper Ore. Clearly exports of iron ore and coal (which comprise the bulk commodity sub-index) dominate the other commodities of the non-rural sub-index and thus drive its value. As linearity between explanatory variables is a violation of assumption 2, only one of these sub-indices should be included in the model. Thus models 2 and 3 exclude the bulk commodity $(\triangle \ln C o m B C)$ and non-rural commodity $(\Delta \operatorname{lnComNR})$ sub-indices respectively.

Table 2. Model 2 coefficients

\begin{tabular}{lcccc}
\hline & Estimate & Std. Error & $\mathrm{t}$ value & $\operatorname{Pr}(>|\mathrm{t}|)$ \\
\hline (Intercept) & 0.00133 & 0.00149 & 0.89223 & 0.37283 \\
$\Delta \operatorname{lnComR}$ & -0.24316 & 0.04815 & -5.04982 & 0.000001 \\
$\Delta \operatorname{lnComNR}$ & -0.44776 & 0.05075 & -8.82275 & 0 \\
$\Delta \operatorname{lnComBM}$ & 0.06563 & 0.03392 & 1.93491 & 0.05374 \\
\hline
\end{tabular}

Table 3. Model 3 coefficients

\begin{tabular}{lcccc}
\hline & Estimate & Std. Error & $\mathrm{t}$ value & $\operatorname{Pr}(>|\mathrm{t}|)$ \\
\hline (Intercept) & 0.00117 & 0.00151 & 0.77660 & 0.43788 \\
$\Delta \operatorname{lnComR}$ & -0.25628 & 0.04870 & -5.26265 & 0.0000002 \\
$\Delta \operatorname{lnComNR}$ & -0.04725 & 0.03292 & -1.43529 & 0.15203 \\
$\Delta \operatorname{lnComBC}$ & -0.27531 & 0.03423 & -8.04270 & 0 \\
\hline
\end{tabular}

Table 2 shows the coefficients of model 2 that result when the bulk commodity sub-index is removed. Both the rural and non-rural sub-indices are significant but the base metal sub-index $(\Delta \operatorname{lnComBM})$ also becomes 
significant at the $90 \%$ level. However when the non-rural sub-index is removed in model 3, whose coefficients are shown in Table 3, only the rural and bulk commodity sub-indices are significant.

It is informative to look at the sign of the base-metal coefficient in the two models, as it is positive in model 2 and negative in model 3. A negative coefficient indicates that as the price of a basket of commodities decreases, the value of the AUD increases. This intuitively makes sense as cheaper commodities could lead to an increase in world demand and thus an increase in demand for the AUD. It therefore is more meaningful for the base-metal coefficient to be negative and that its significance at the $90 \%$ level in model 2 is debatable. As a result a fourth model removing the base-metal sub-index from model 2 was created. Its coefficients as well as those of the previous models are shown in Table 4.

Table 4. Model comparison

\begin{tabular}{lcccc}
\hline & \multicolumn{4}{c}{ Dependent variable: } \\
& $(1)$ & $(2)$ & $(3)$ & $(4)$ \\
\cline { 2 - 5 } & $-0.24303^{* * *}$ & $-0.24316^{* * *}$ & $-0.25628^{* * *}$ & $-0.23373^{* * *}$ \\
\cline { 2 - 5 }$\Delta \ln$ ComR & $(0.04821)$ & $(0.04815)$ & $(0.04870)$ & $(0.04808)$ \\
& $-0.41380^{* * *}$ & $-0.44776^{* * *}$ & & $-0.41802^{* * *}$ \\
& $(0.12306)$ & $(0.05075)$ & & $(0.04854)$ \\
$\Delta \ln$ ComNR & 0.05676 & $0.06563^{*}$ & -0.04725 & \\
& $(0.04485)$ & $(0.03392)$ & $(0.03292)$ & \\
$\Delta \operatorname{lnComBC}$ & -0.02479 & & $-0.27531^{* * *}$ & \\
& $(0.08180)$ & & $(0.03423)$ & \\
Constant & 0.00132 & 0.00133 & 0.00117 & 0.00143 \\
& $(0.00149)$ & $(0.00149)$ & $(0.00151)$ & $(0.00149)$ \\
& 384 & 384 & 384 & 384 \\
Observations & 0.25955 & 0.25937 & 0.23745 & 0.25207 \\
$\mathrm{R}^{2}$ & 0.25173 & 0.25352 & 0.23143 & 0.24814 \\
\hline Adjusted $\mathrm{R}^{2}$ & & & &
\end{tabular}

Note. ${ }^{*} \mathrm{p}<0.1 ;{ }^{* *} \mathrm{p}<0.05 ;{ }^{* * *} \mathrm{p}<0.01$.

Comparing the adjusted $\mathrm{R}^{2}$ values in Table 4 to assess each model's goodness of fit, it is clear that model 2 is superior to model 1 as it explains more of the exchange rate data with less variables. The fact that model 2 has a higher $\mathrm{R}^{2}$ value than model 3 indicates that the non-rural commodity sub-index has better explanatory power for changes in exchange rate than the bulk commodity sub-index. This is unsurprising given that the non-rural sub-index encapsulates the bulk commodity sub-index as well as additional commodities. Finally, there is a small decrease in the adjusted $\mathrm{R}^{2}$ value from model 2 to model 4 when the base metal sub-index is removed. To aid comparison, an F-test was conducted on the two models with the ANOVA function in R. The results are shown in Table 5.

Table 5. F-test of models 2 and 4

\begin{tabular}{lllllll}
\hline & Res.Df & RSS & Df & Sum of Sq & F & $\operatorname{Pr}(>\mathrm{F})$ \\
\hline 2 & 380 & 0.319 & & & & \\
4 & 381 & 0.322 & -1 & -0.003 & 3.744 & 0.054 \\
\hline
\end{tabular}

The p-value of $0.054>0.05$ indicates that the two models are not sufficiently different and that there is no advantage in having the base metal sub-index term in model 2. However it is a borderline case.

In order to better capture changes in the exchange rate, the ' $\operatorname{lnBoT}$ ' is added as an explanatory variable to the model. It is thought that by capturing some information about the selling of AUD to buy imports, a higher adjusted $\mathrm{R}^{2}$ value could be achieved. However as BoT data is only available from January 1988, the sample size of all other variables are shortened accordingly (represented by an appended ' $x$ ' to the variable names). The bulk commodity sub-index has been omitted from the next model as it still correlates strongly with the non-rural sub-index $(0.8539)$ and because the non-rural sub index better captures changes in the exchange rate. Model 5 thus has the following form: 


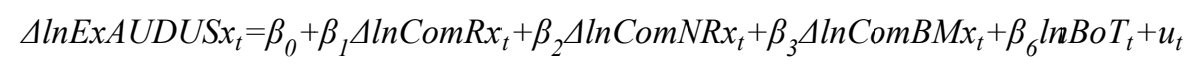

Table 6. Model 5

\begin{tabular}{lcccc}
\hline & Estimate & Std. Error & $\mathrm{t}$ value & $\operatorname{Pr}(>|\mathrm{t}|)$ \\
\hline (Intercept) & 0.00135 & 0.00162 & 0.83346 & 0.40522 \\
$\Delta \operatorname{lnComRx}$ & -0.21906 & 0.05037 & -4.34860 & 0.00002 \\
$\Delta \operatorname{lnComNRx}$ & -0.43497 & 0.05150 & -8.44664 & 0 \\
$\Delta \operatorname{lnComBMx}$ & 0.10547 & 0.03557 & 2.96480 & 0.00326 \\
$\Delta \operatorname{lnBoTx}$ & -0.02782 & 0.01391 & -1.99915 & 0.04646 \\
\hline Observations: 318 & & & & \\
$\mathrm{R}^{2}=0.2723$ & & & & \\
Adjusted $\mathrm{R}^{2}=0.263$ & & & \\
\hline
\end{tabular}

Table 6 is a summary of Model 5. It can be seen that in addition to the rural and non-rural commodity sub-indices being significant, the base metal sub-index is now also significant with a positive coefficient over this shorter sample period. This is in stark contrast to earlier models. The ' $\operatorname{lnBoT}$ ' variable is also significant on a $95 \%$ level with a small negative coefficient. But most importantly, the model's adjusted $\mathrm{R}^{2}$ vallue has increased by a percentage point over model 2 , indicating that it is capturing more of the changes in exchange rate than previous models. A plot of model 5 over the AUD/USD exchange rate is shown in Figure 11.

To ensure that model 5 is valid and meets the assumptions discussed in methodology, some plots and statistics on the error term $u_{t}$ were calculated. First, Figure 12 shows a plot of residuals against fitted values to check if the residuals have a zero mean and constant variance (homoscedasticity). The residuals seem to be evenly spread above and below zero with fairly constant variance, indicating that assumption 3 and 4 may be met.

Second, plots of residuals against each explanatory variable used in model 5 are shown in Figure 13 to ensure that there is no correlation between the residuals and explanatory variables. The plots indicate that the error term is independent of these variables.

Third, assumption 5 is tested, which is that there is no serial correlation of the error term across time. As a first indication, the Durbin-Watson statistic was computed and resulted in a value of 2.263, which is close to the ideal value of 2 , indicating that no serial correlation is present when the error term is regressed against its first lag. If anything, the model is slightly over-differenced. To gain a more complete picture, the autocorrelation and partial autocorrelation of the error term across 12 lags (representing 12 months) was computed and the results shown in Figures 14 and 15 . There seems to be some autocorrelation at lag 3, which corresponds to a quarterly time period. That may reflect some seasonal effects not taken into account by this model.

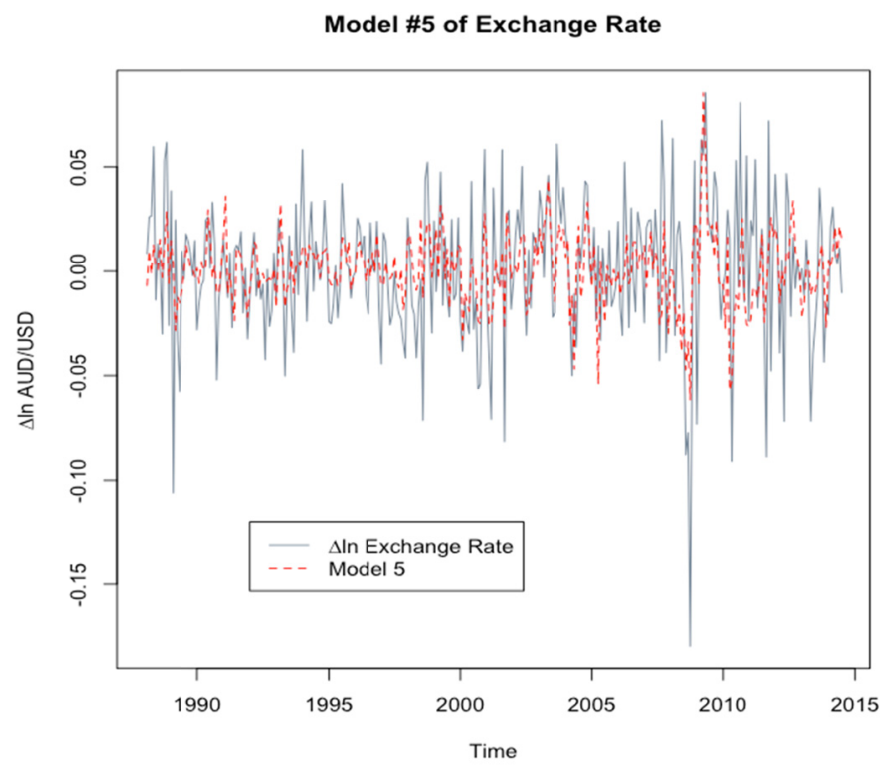

Figure 11. Plot of model 5 on top of exchange rate 


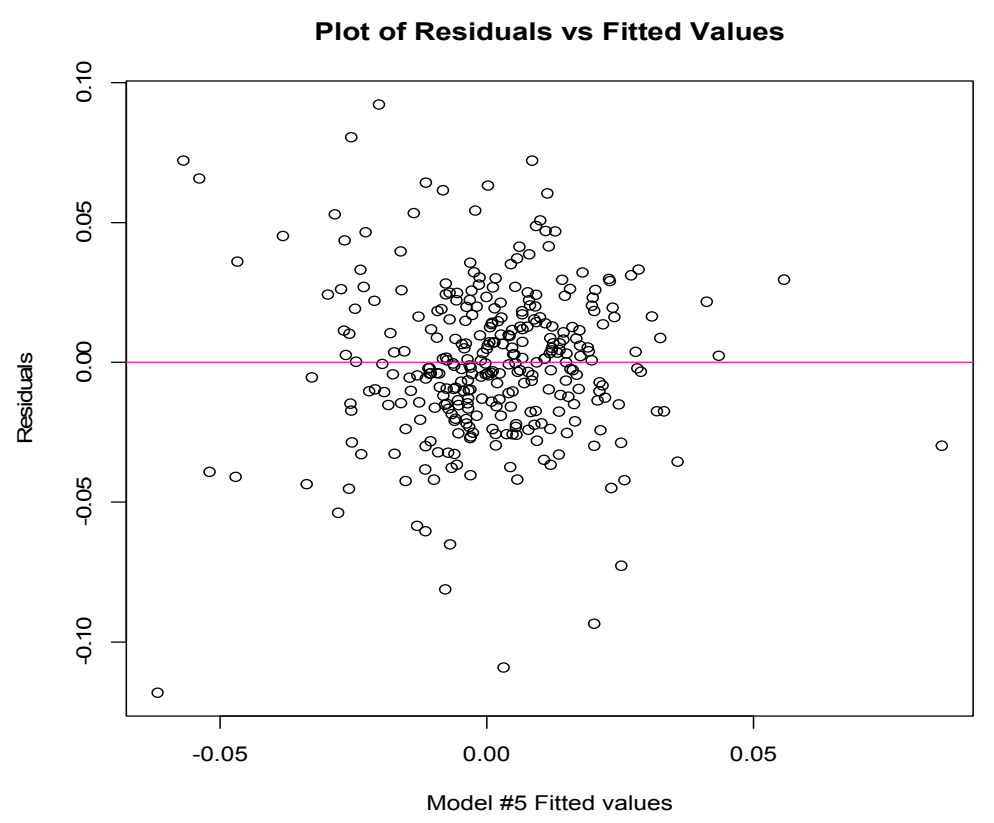

Figure 12. Plot of residuals against fitted values

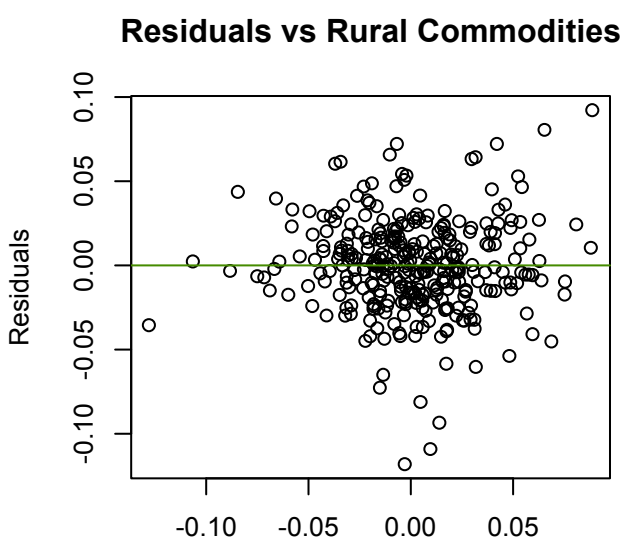

$\Delta$ In Rural Commodities

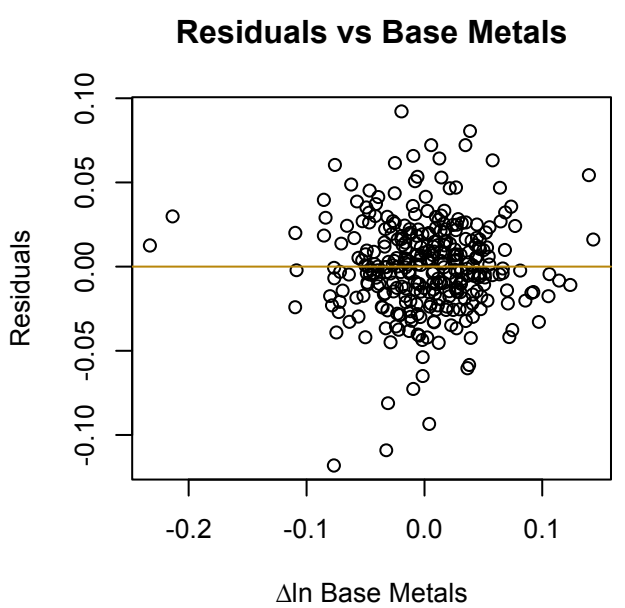

\section{Residuals vs Non-Rural Commodities}

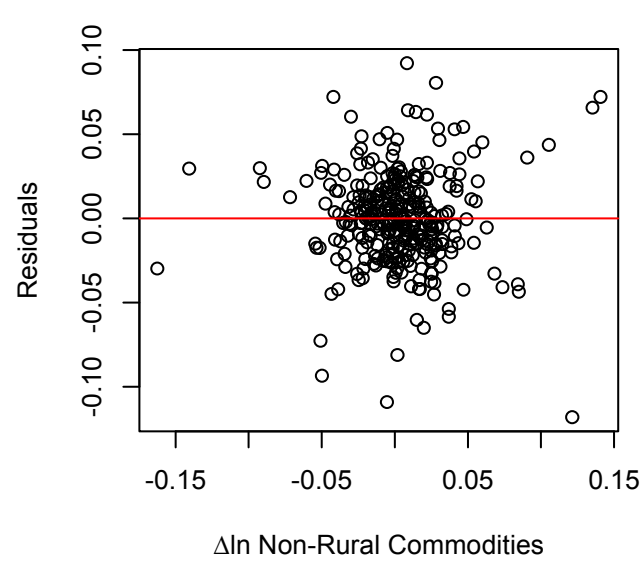

Residuals vs Balance of Trade

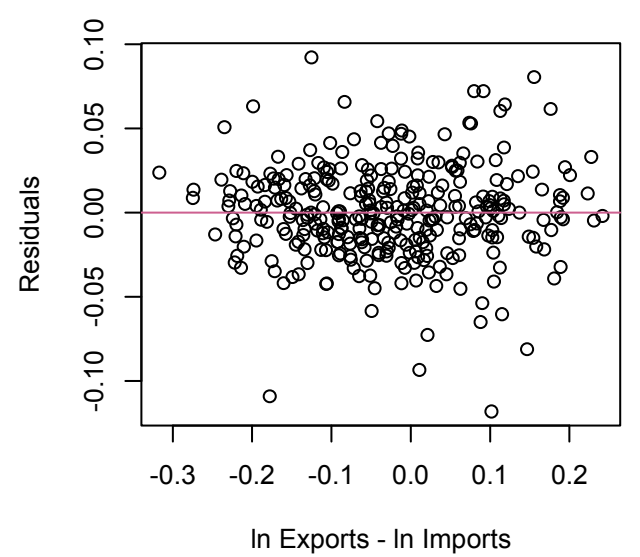

Figure 13. Plot of residuals against explanatory variables 


\section{Autocorrelation of Model \#5 Residuals}

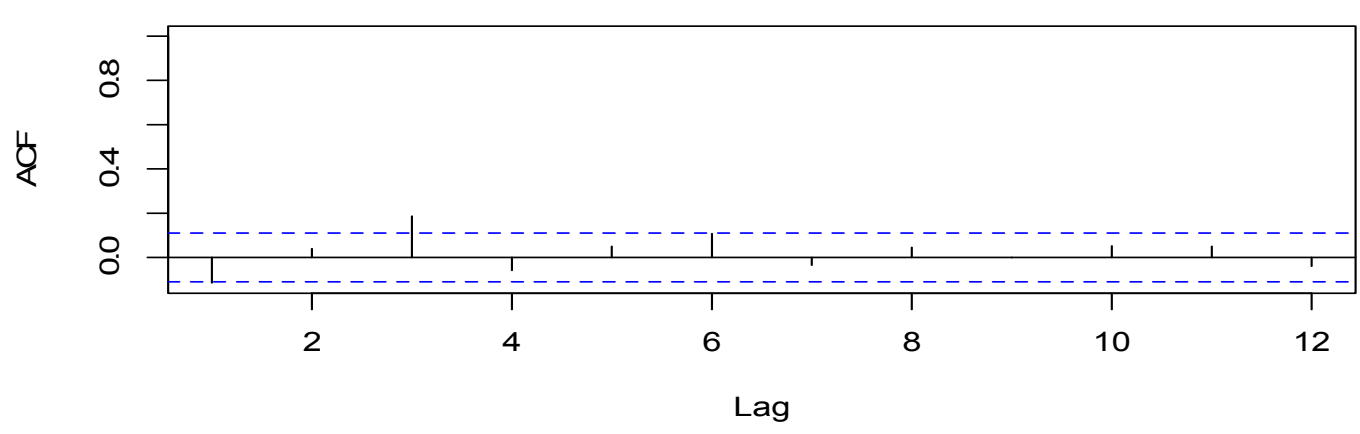

Figure 14. Autocorrelation of the error term across 12 lags

Partial Autocorrelation of Model \#5 Residuals

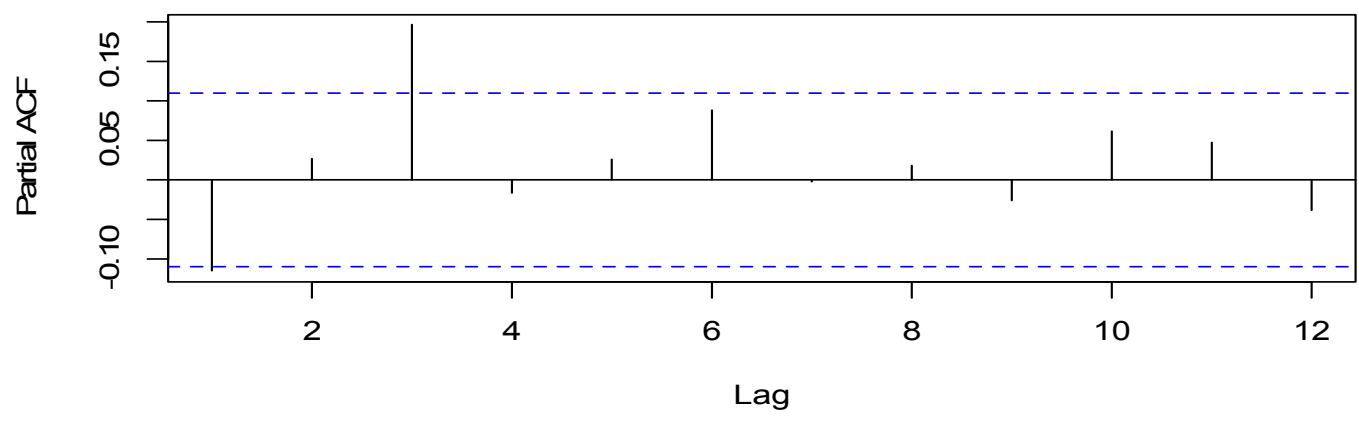

Figure 15. Partial autocorrelation of the error term across 12 lags

Finally, assumption 6 is tested, which is that the error term should follow a normal distribution. This is checked with two plots. The first, shown in Figure 16 is a histogram of the standardized residuals. The second, shown in Figure 17 is a QQ plot. As can be seen, the residuals do seem to follow a normal distribution on a whole, although the QQ plot detects some divergence from normality at the tails.

\section{Histogram of Residuals}

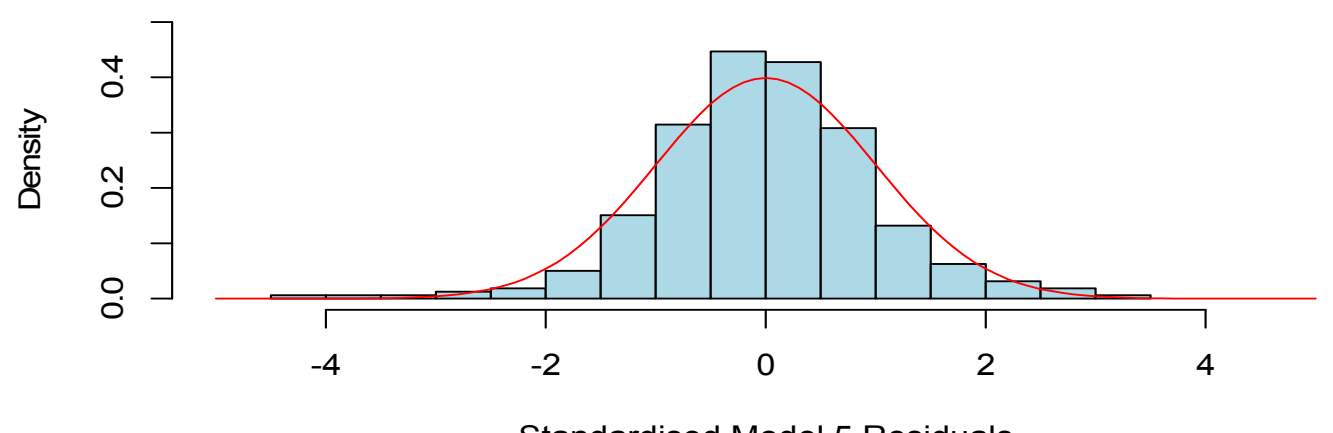

Standardised Model 5 Residuals

Figure 16. Histogram of residuals 


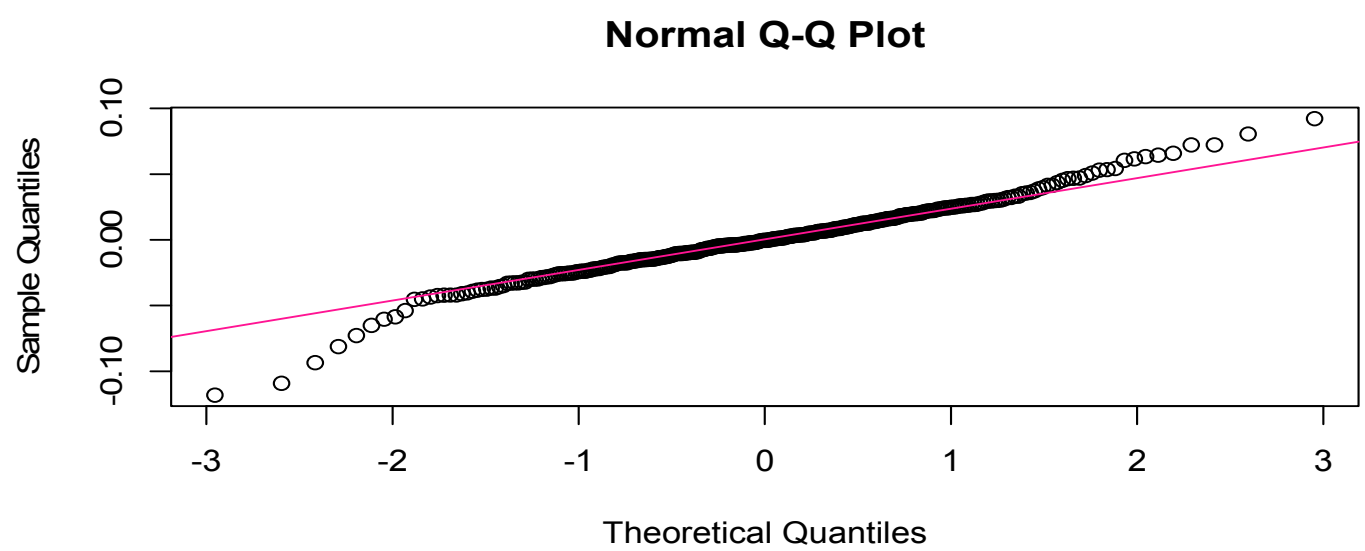

Figure 17. Q-Q plot of residuals

\section{Conclusion}

After taking the natural logarithm of the AUD/USD exchange rate, commodity sub-indices, total exports and total imports, the data were first differenced to make them stationary and weakly dependent. Regression models were then constructed using the method of OLS to express changes in exchange rate with the changes in each of the commodity sub-indices and the ' $\operatorname{lnBoT}$ '.

It was found that when only taking commodity sub-indices over the sample period July 1982 to July 2014, it was unclear whether the best regression model included the base metal sub-index or not. What was apparent was that the non-rural commodity sub-index had the greatest explanatory power for changes in exchange rate as it had the largest coefficient, almost double in magnitude to that of the rural commodity sub-index. This is unsurprising given that the non-rural sub-index contains the commodities within the base metal and bulk commodity indices as well as LNG, Crude Oil, Alumina, Gold and Copper Ore.

After including the ' $\operatorname{lnBoT}$ ' and reducing the sampling period to January 1988 to July 2014, model 5 was found to have greatest adjusted $\mathrm{R}^{2}$ value of 0.263 among all the models generated. This may be more due to the reduction in sample size rather than the insertion of ' $\operatorname{lnBoT}$ ' since its coefficient is small and significance to the model borderline at the $95 \%$ level. Visually from Figure 2, it can be seen that from around the year 2000 onward, the change in exchange rate seems to match changes in the non-rural and bulk commodity sub-indices, whereas prior to that time, there seems to be very little correlation between changes in the exchange rate and changes in any of the commodity sub-indices.

Thus, by shortening the sampling period, less of the uncorrelated section of time is modelled, leading to a greater $\mathrm{R}^{2}$ value.

This makes sense since Australia has experienced a commodities boom since 2000, where the total value of exports has increased exponentially (see Figure 3) and commodities have contributed a greater proportion to that total value. This means that commodities would have a greater impact on the exchange rate since the start of the boom. An interesting study would be to model the AUD/USD exchange rate from the year 2000 to present and see if a higher correlation is found with commodity prices.

\section{References}

ABS. (2014a). TABLE 31. MERCHANDISE EXPORTS, Broad Economic Category, FOB Value. Series ID: A1829284C, in 5368.0 International Trade in Goods and Services, Australia.

ABS. (2014b). TABLE 31. MERCHANDISE IMPORTS, Broad Economic Category, Customs Value. Series ID: A1829664F, in 5368.0 International Trade in Goods and Services, Australia.

Chan, K., Tse, Y., \& Williams, M. (2011). The Relationship between Commodity Prices and Currency Exchange Rates: Evidence from Futures Markets. In A. R. T. Ito (Ed.), Commodity Prices and Markets, East Asia Seminar on Economics (pp. 47-71). Editor: University of Chicago Press.

Chen, Y., Rogoff, K., \& Rossi, B. (2010). Can Exchange Rates Forecast Commodity Prices? The Quarterly Journal of Economics, 125(3), 1145-1194. http://dx.doi.org/10.1162/qjec.2010.125.3.1145

RBA. (2014a). Commodity Prices-I2, 20/08/2014. Retrieved from http://www.rba.gov.au/statistics/tables/-inflation-expectations 
RBA. (2014b). Exchange Rates-Monthly-July 1969 to December 2009, 20/08/2014. Retrieved from http://www.rba.gov.au/statistics/historical-data.html-exchange-rates

RBA. (2014c). Exchange Rates-Monthly-January 2010 to latest completed month of current year, 20/08/2014. Retrieved from http://www.rba.gov.au/statistics/historical-data.html-exchange-rates

Robinson, H. W. T. (2013). Changes to the RBA Index of Commodity Prices. Retrieved from http://www.rba.gov.au/publications/bulletin/2013/mar/3.html

Simpson, J. (2002). The Relationship between Commodity Prices and the Australian Dollar in London Meetings, EFMA. http://dx.doi.org/10.2139/ssrn.314872

Wooldridge, J. M. (2013). Introductory Econometrics: A Modern Approach (5th ed.). Mason, Ohio: South-Western Cengage learning: 881.

\section{Note}

Note 1. Rural Commodities include: Wool, Beef /Veal, Wheat, Barley, Canola, Sugar, Cotton and Lamb/Mutton. Base Metals include: Aluminium, Lead, Copper, Zinc and Nickel. Bulk Commodities include: Iron Ore, Metallurgical Coal and Thermal Coal. Non-Rural Commodities include Base Metals, Bulk Commodities, LNG, Crude Oil, Alumina, Gold and Copper Ore.

\section{Copyrights}

Copyright for this article is retained by the author(s), with first publication rights granted to the journal.

This is an open-access article distributed under the terms and conditions of the Creative Commons Attribution license (http://creativecommons.org/licenses/by/3.0/). 